\title{
INEQUALITIES FOR MEAN VALUES OVER QUASIBALLS FOR FUNCTIONS DEFINED ON ARBITRARY OPEN SETS
}

\author{
V. I. BURENKOV AND T. V. TARARYKOVA
}

Abstract. Sharp two-sided estimates for mean values over quasiballs are established, which allow reducing the problem of obtaining certain weighted integral inequalities for arbitrary open sets to appropriate inequalities for quasiballs.

Mathematics subject classification (2000): 26D10.

Key words and phrases: Inequalities, reqular quasidistance, mean values over quasiballs.

\section{REFERENCES}

[1] E. M. STEIN, Singular integrals and differentiabilty properties of functions, Princeton University Press, 1970.

[2] M. DE GuZMÁN, Differentiation of integrals in $\mathbb{R}^{n}$, Springer-Verlag, 1975.

[3] I. S. GradshteIn, I. M. RYZHIK, Table of integrals, series, and products, Academic Press, 1980. 